\title{
ÍNDICE
}

Dossier temático:

\section{Mujeres latinoamericanas revolucionarias. Biografias, escritura testimonial y militancia}

\author{
Coordinación: Cristina Viano
}

\section{$\checkmark$ PRESENTACIÓN}

$\checkmark$ Género, biografia e historia oral o de cómo contar la vida de Ana María Villareal de Santucho

ANDREA ANDÚJAR - DÉBORA D`ANTONIO - MÓNICA GATICA

$\checkmark$ Tras las huellas de Diana Triay: explorando la participación de las mujeres en el PRT-ERP VIOLETA AYLES TORTOLINI

$\checkmark$ Las chichises se organizan: militancia en los frentes de mujeres del PRT-ERP y Montoneros (Córdoba, 1973-1974)

ANA LAURA NOGUERA

$\checkmark$ Victimidad estratégica, Comisión de la Verdad, Género y Memoria en el Perú. Escritura testimonial de prisioneras políticas del PCP-Sendero Luminoso sobrevivientes a la dictadura de Fujimori (2001) ANOUK GUINÉ

\section{ARTÍ́culOS}

$\checkmark$ Elites y artesanos a través del pensamiento politico intelectual de John Adams y Thomas Paine JOAQUINA DE DONATO LOZANO

$\checkmark$ Política Obrera de cara a la lucha armada en Latinoamérica y sus diversas expresiones en los años sesenta SEBASTIÁN F. PARIS

$\checkmark$ "Los vegetales que viven en la República". El estudio de la flora uruguaya en Anales del Museo Nacional de Montevideo, 1894-1925

\section{RODRIGO ANTONIO VEGA Y ORTEGA BAEZ}




\section{RESEÑAS DE LIBROS}

$\checkmark$ Nieto, Agustín y Videla, Oscar (2018). El anarquismo después del anarquismo. Una historia espectral. Mar del Plata: Ed. GESMar (Grupo de Estudios Sociales Maritimos) $1^{\circ}$ ed. Disponible en: https://gesmar.estudiosmaritimossociales.org/editorial/coleccionanarquismos/el-anarquismo-despues-del-anarquismo/ FLORENCIA MANGOLD

$\checkmark$ Watts, Edward J. (2019). República mortal. Cómo cayó Roma en la tiranía. Barcelona: Galaxia Gutemberg [320 páginas] NICOLÁS BOCASSO 